\title{
ISW for the Treatment of Deviated and Rotated Teeth
}

\author{
Chun-shuo HUANG ${ }^{1,2}$, Jian-hong YU ${ }^{* 1,2}$ \\ ${ }^{1}$ Department of Orthodontics, China Medical University and Medical Center, Taiwan, R.O.C. \\ ${ }^{2}$ School of Dentistry, College of Dentistry, China Medical University, Taiwan, R.O.C.
}

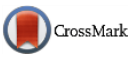

\begin{abstract}
The objective of the case study is for the treatment of deviated and rotated teeth by ISW (Improved Super-elastic Ti-Ni alloy wire, developed by Tokyo Medical and Dental University). An adult female (37 years old) came to our clinic with a chief complaint of abnormal tooth axis of lower arch combined with spacing and rotation of other teeth. This patient mentioned she didn't care about the problem of facial asymmetry. By using ISW, lower deviated teeth were corrected rapidly. Rotation of lower left and right premolars were corrected simply by ISW leveling. For correction of rotated upper left second premolar, we placed a bracket on the mesial surface of \#25 temporarily and Ni-Ti open coil-spring was placed in between \#25 and \#26 in order to increase inter-bracket span so as to create space for bracket bonding on the buccal surface. ISW was fully engaged into \#25 and then rotation was corrected by further leveling. After 18 months of active treatment, a stable occlusion and a desirable esthetic outcome was achieved and the patient was pleased with the treatment result after the active treatment.
\end{abstract}

Keywords: ISW, de-rotation, open coil-spring, not-in-slot, correction of tooth axis, unilateral MEAW, molar mesialization, inter-maxillary elastics (IME),

\section{Introduction}

Correction of rotation teeth has long been a challenging issue for orthodontists over years. ${ }^{[1-6]}$ There are some important concepts for retention of rotated teeth as following: (1) rotations must be corrected by over-rotation in the opposite direction; (2) rotated teeth must be retained over an especially long period of time, preferably with a fixed retainer; (3) a properly equilibrated occlusion will practically eliminate retention worries.

Nevertheless, the critical clinical treatment alternative of correcting rotated teeth should be the relative tipping and torqueing simultaneously to prevent further insufficient orthodontic reciprocal forces and correlated periodontal problems. Therefore, the long term retention method of corrected rotated teeth should include particular malocclusion, habits related to the mouth, the actual cuspal anatomy of the teeth involved, the health of the periodontium, muscular pressures in the oral region, problems of apical base limitations, facial growth changes, and perhaps even atmospheric pressure. ${ }^{[7-12]}$

\section{History and Diagnosis}

An adult 37-year-old female came to our clinic with a chief complaint of abnormal tooth axis of lower arch combined with spacing and rotation of other teeth. Her lateral profile was convex with mandible shifted to the left side (Fig 1). Clinical examination revealed right side Class III and left side Class I molar relationship, \#25 rotation and \#35 lingually tipped due to dental compensation. (Fig 2). Panoramic film showed \#14, \#24, \#44, \#38 missing teeth and abnormal tooth axis of lower arch combined with spacing and rotation of other teeth (Fig 3).
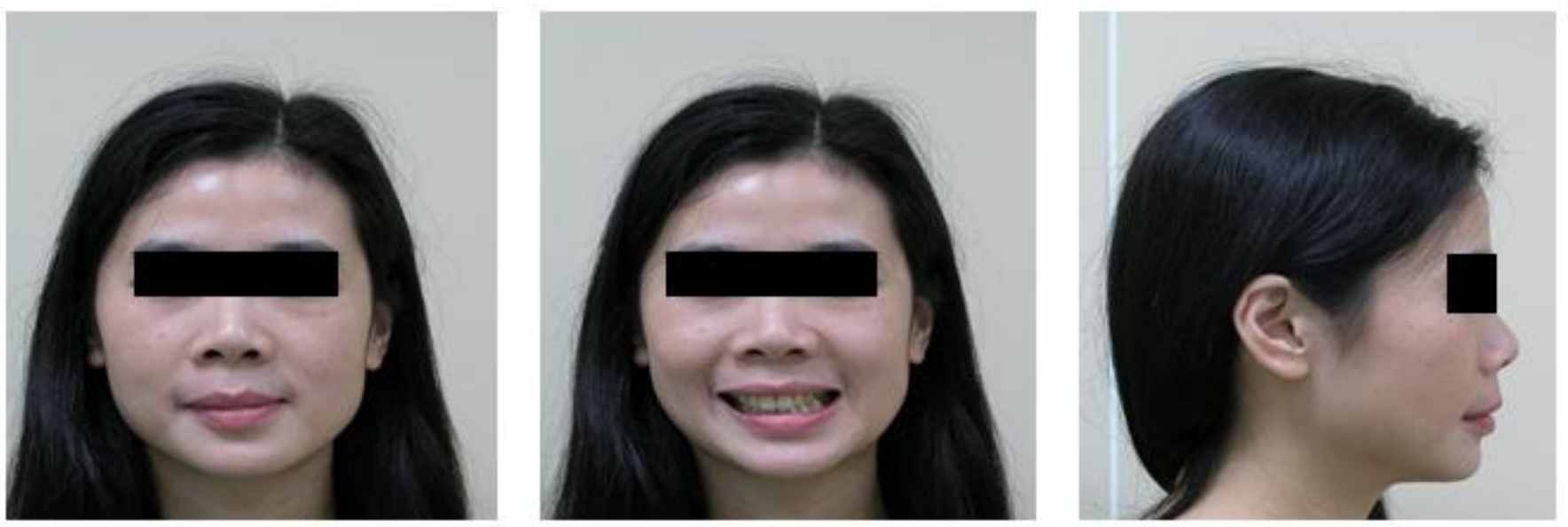

Figure 1 : Facial photos before active treatment 


\section{International Journal of Innovative Research in Medical Science (IJIRMS) \\ Volume 04 Issue 01 Jan 2019, ISSN: 2455-8737, Imp. Factor - 4.102 \\ Available online at $-\underline{w w w . i j i r m s . i n}$}

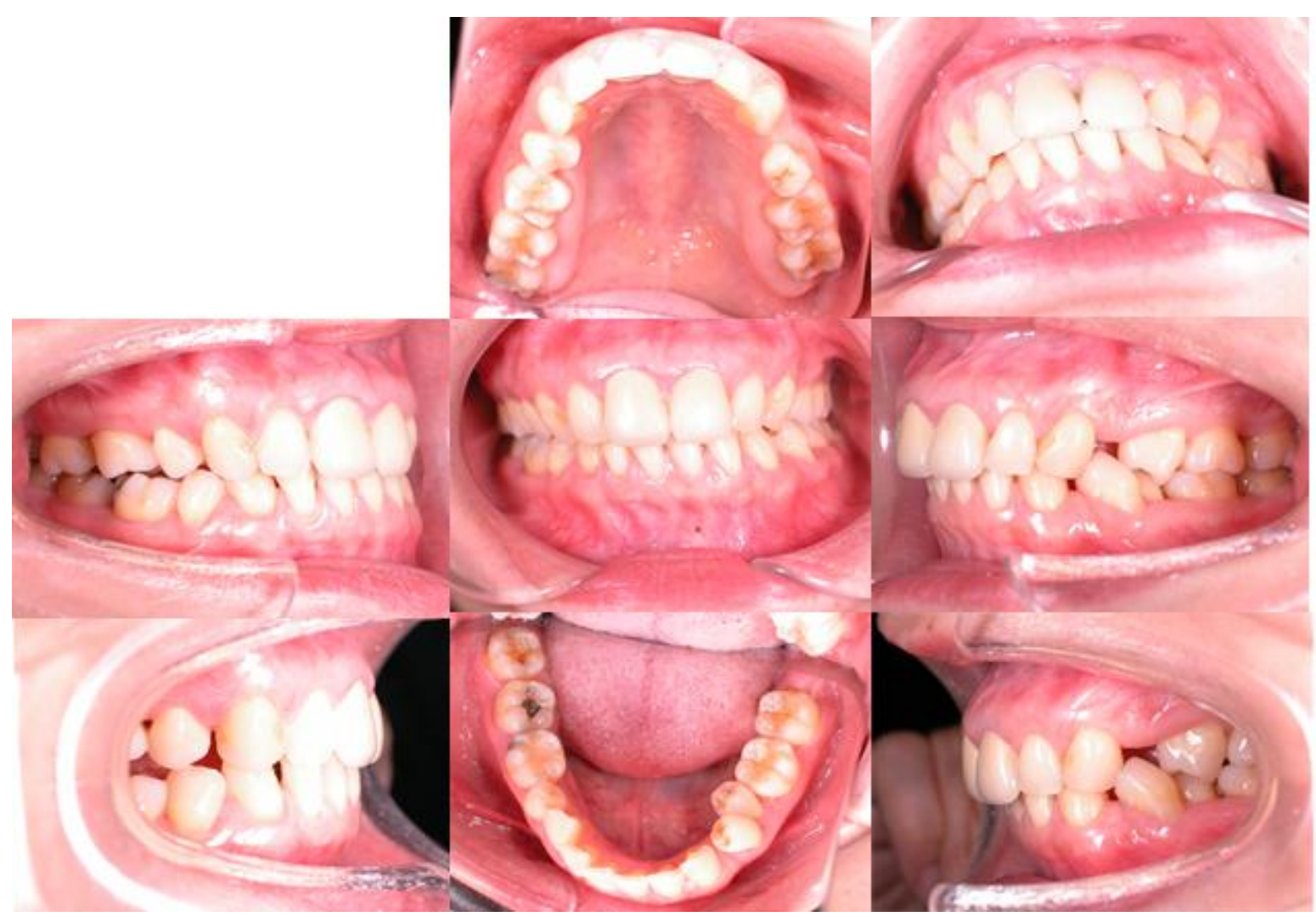

Figure 2 : Intraoral photos before active treatment

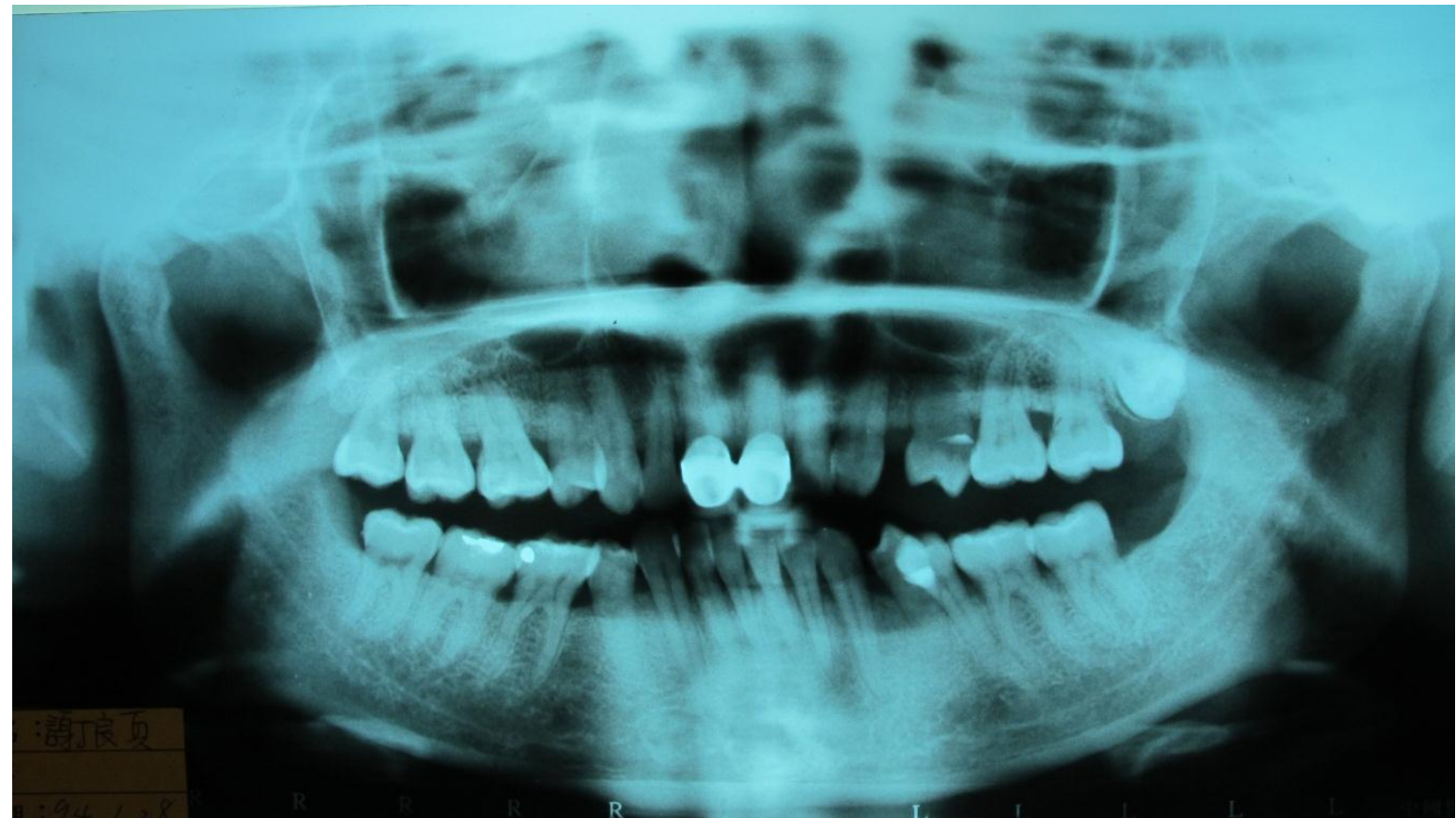

Figure 3 : Panoramic film before active treatment

The radiographic methods of the research include intraoral photos, lateral cephalometric projection and panoramic x-ray films. Also the cephalometric analyses before and after the treatment were presented in this case. The cephalometric analysis showed a skeletal Class II jaw relationships (SNA : $89.3^{\circ}$ 、SNB : $81.9^{\circ}$ 、 ANB : $7.4^{\circ)}$ and dental compensation (U1 to FH plane : $106.5^{\circ}$, Inter-incisal angle : $138.0^{\circ}$ ). The low angle skeletal pattern can be seen prominently in the polygon (Gonial angle : $110.6^{\circ}$ )(Fig 4 and Fig 5).
Therefore, the summary of diagnosis includes

1. Functional (-)

2. Skeletal $( \pm): \operatorname{SNA}\left(89.3^{\circ}\right), \operatorname{SNB}\left(81.9^{\circ}\right), \mathrm{ANB}=7.4^{\circ}$, skeletal Class II Gonial angle $=110.6^{\circ}$

3. Denture (-) : U1 to FH plane $\left(106.5^{\circ}\right)$, inter-incisal angle $\left(138.0^{\circ}\right)$, abnormal tooth axis of lower arch

4. Dental (+) : \#14, \#24, \#44, \#38 missing

5. Discrepancy $(+)$ : upper: R't: $-0.5 \mathrm{~mm} / \mathrm{L}$ 't: $+4.0 \mathrm{~mm}$

lower: R't: $-1.5 \mathrm{~mm} / \mathrm{L}$ 't: $-4.0 \mathrm{~mm}$ 
International Journal of Innovative Research in Medical Science (IJIRMS)

Volume 04 Issue 01 Jan 2019, ISSN: 2455-8737, Imp. Factor - 4.102

Available online at - www.ijirms.in

\section{5-01-28}
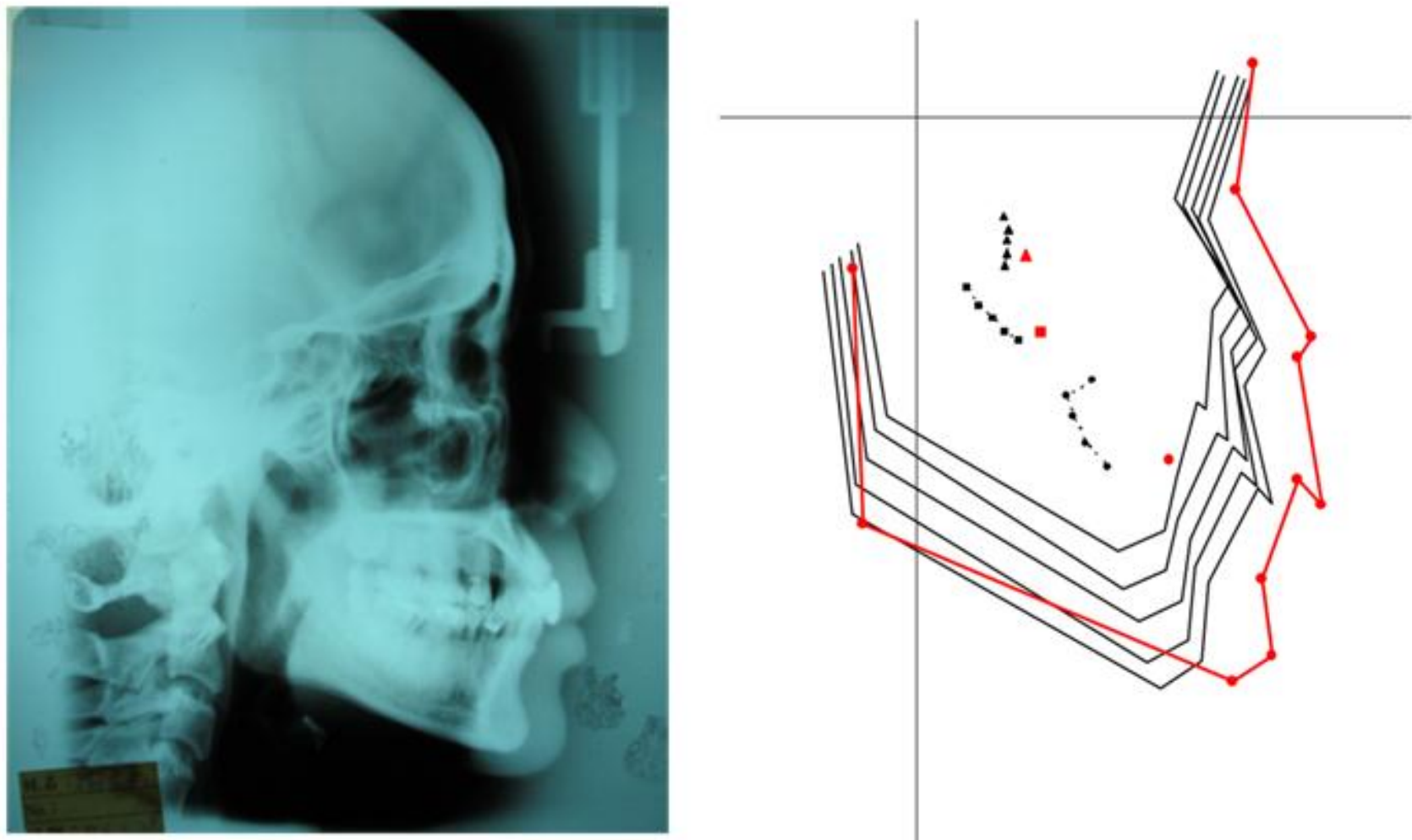

Figure 4 : Lateral cephalometric film before active treatment

\section{Polygon- before active treatment}

\begin{tabular}{|c|c|c|c|}
\hline & Value & Mean. & S.D \\
\hline Facial angle & 91.9 & 84.83 & 3.05 \\
\hline Convexity & 13.2 & 7.58 & 4.95 \\
\hline A-B plane & -10.7 & -4.81 & 3.50 \\
\hline Mandibular plane & 20.6 & 28.81 & 5.23 \\
\hline $\mathrm{Y}$-axis & 58.4 & 65.38 & 5.63 \\
\hline Occlusal plane & 12.8 & 11.42 & 3.64 \\
\hline Interincisal & 138.0 & 124.09 & 7.63 \\
\hline L-1 to Occlusal & 12.6 & 23.84 & 5.28 \\
\hline L-1 to Mandibular & 94.8 & 96.33 & 5.78 \\
\hline U-1 to A-P plane & 7.4 & 8.92 & 1.88 \\
\hline FMIA & 64.5 & 54.63 & 6.47 \\
\hline $\mathrm{FH}$ to $\mathrm{SN}$ plane & 9.2 & 6.19 & 2.89 \\
\hline SNA & 89.3 & 82.32 & 3.45 \\
\hline SNB & 81.9 & 78.90 & 3.45 \\
\hline SNA-SNB diff. & 7.4 & 3.39 & 1.77 \\
\hline $\mathrm{U}=1$ to $\mathrm{N}-\mathrm{P}$ plane & 11.0 & 11.74 & 2.73 \\
\hline $\mathrm{U}-1$ to $\mathrm{FH}$ plane & 106.5 & 111.13 & 5.54 \\
\hline $\mathrm{U}-1$ to $\mathrm{SN}$ plane & 97.3 & 104.54 & 5.55 \\
\hline Gonial angle & 110.6 & 122.23 & 4.61 \\
\hline Ramus inclination & 90.0 & 87.07 & 4.40 \\
\hline
\end{tabular}

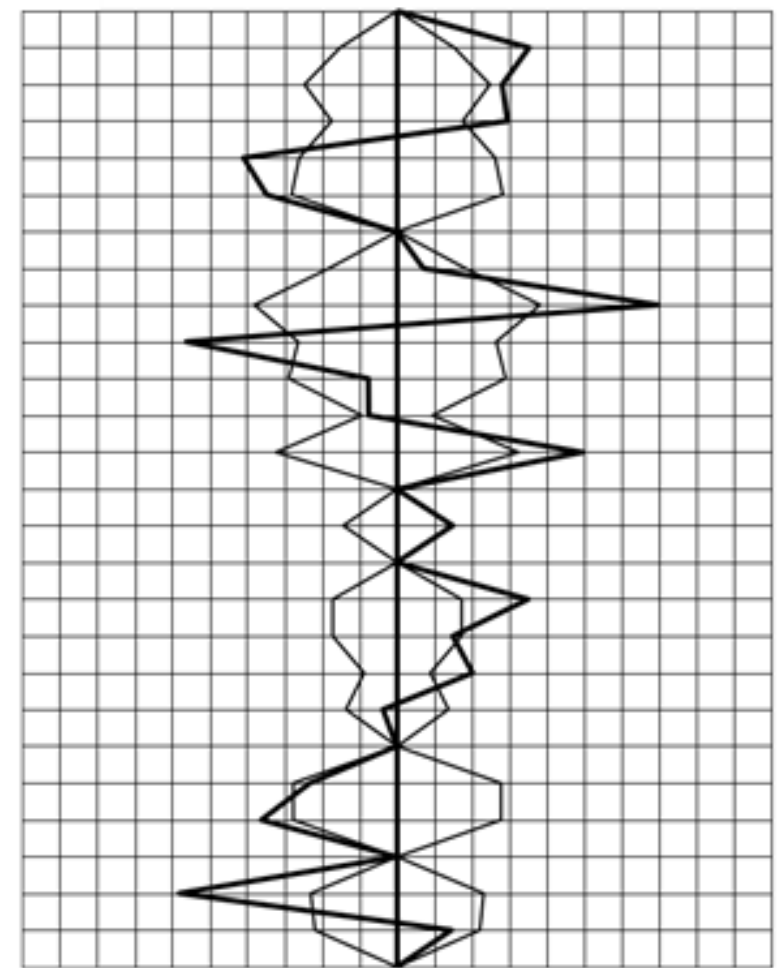

Figure 5 : Polygon before active treatment 


\section{International Journal of Innovative Research in Medical Science (IJIRMS) \\ Volume 04 Issue 01 Jan 2019, ISSN: 2455-8737, Imp. Factor - 4.102 \\ Available online at $-\underline{w w w . i j i r m s . i n}$}

\section{Treatment Objectives}

Our treatment objectives were (1) to improve facial profile, (2) to establish appropriate overbite, overjet and arch coordination, (3) to establish indivisualized occlusion

Due to the fact that the patient strongly refused any possibility of orthognathic surgery. Therefore, treatment plan includes:

1. Full mouth DBS (Direct-Bonding System)
2. ISW leveling for correction of teeth axis of lower arch

3. Open coil-spring plus ISW leveling for correction of \#25 rotation

\section{Treatment Progress}

Treatment was started from 2005.03.25. with upper and lower arch DBS and leveling with $0.016 \times 0.022$ ISW with curve added. ISW were fully engaged over lower anterior area for the correction of tooth axis. And the open coil-spring was used between \#23 and \#26 to create space. The elastic chain over \#31-\#34 was used for derotation. (Fig.6)

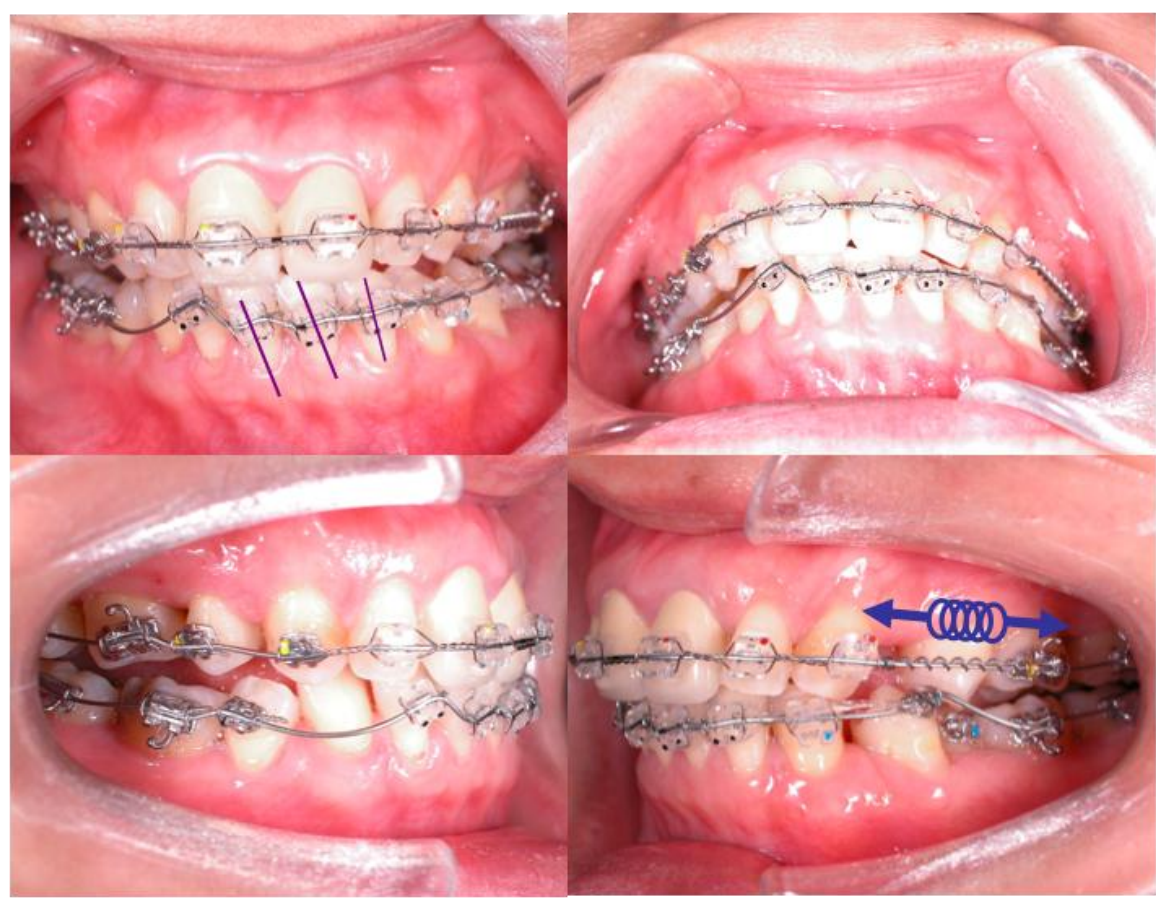

Figure 6 : Period of active treatment: 0 month

On 2005.04.22. After one month of active treatment, the crimpable hook was placed between \#22,\#23 as anchorage and the elastic chain was used to de-rotate \#25. (Fig.7)
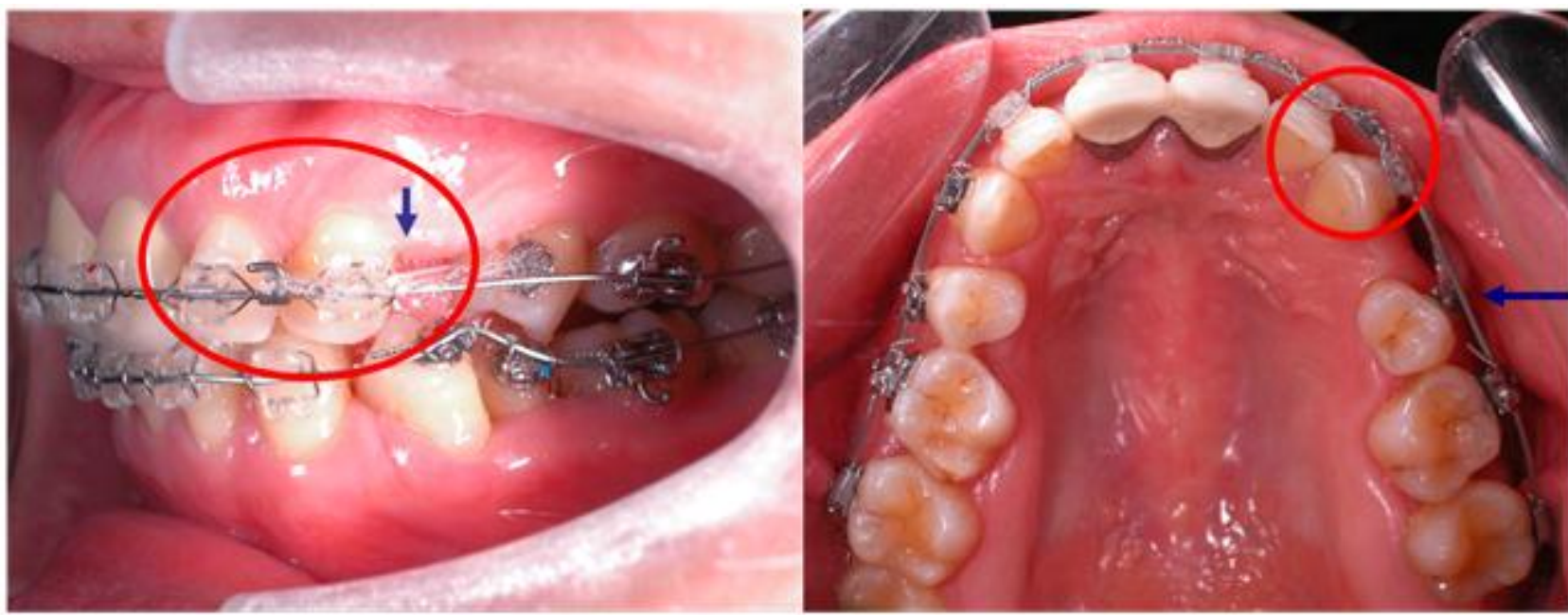

Figure 7: Period of active treatment:1 month

After 2 months of active treatment, on 2005.05.13., tooth axis was corrected and \#25 bracket re-DBS and elastic chain was used for de-rotation. (Fig.8) 
International Journal of Innovative Research in Medical Science (IJIRMS)

Volume 04 Issue 01 Jan 2019, ISSN: 2455-8737, Imp. Factor - 4.102

Available online at $-\underline{w w w . i j i r m s . i n}$

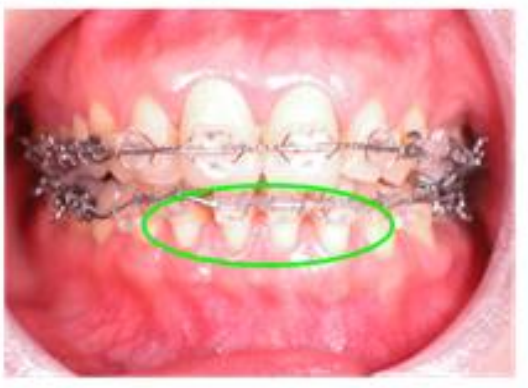

\section{Tooth axis was corrected}

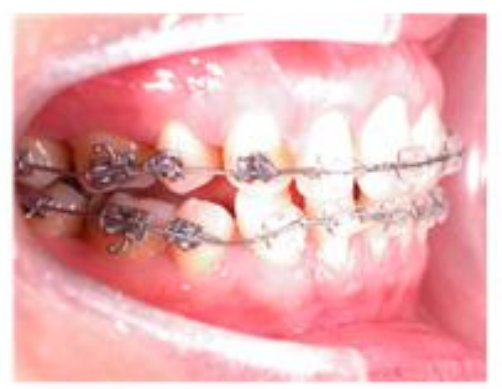

\section{\#25 bracket re-DBS and elastic chain used for de- rotation}
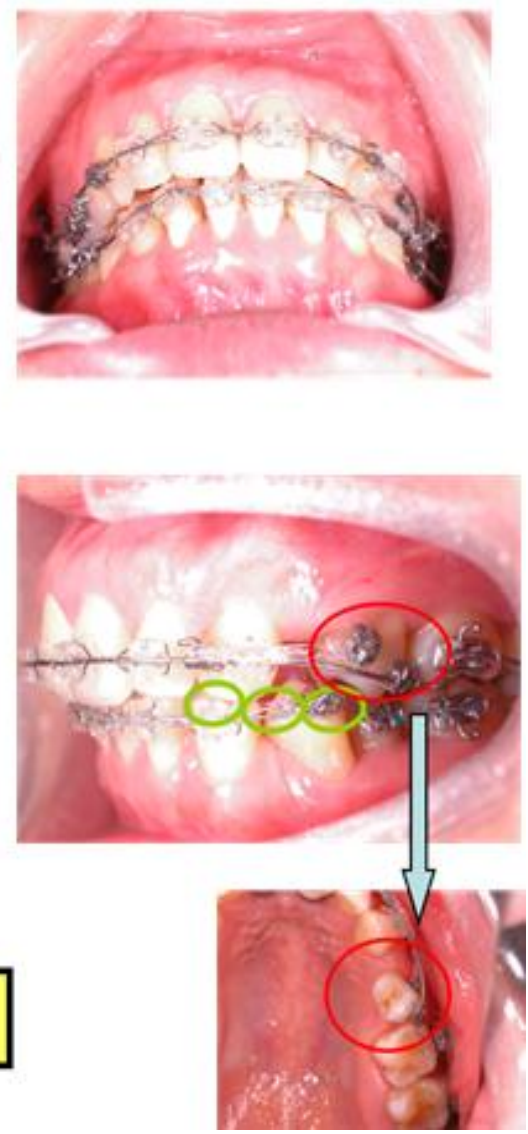

Figure 8: Period of active treatment: 2 month

On 2005.08.12., after 5 months of active treatment, further de-rotation was performed with open coil-spring (100gf) set between \#25 and \#26 to further de-rotate 25. (Fig.9)

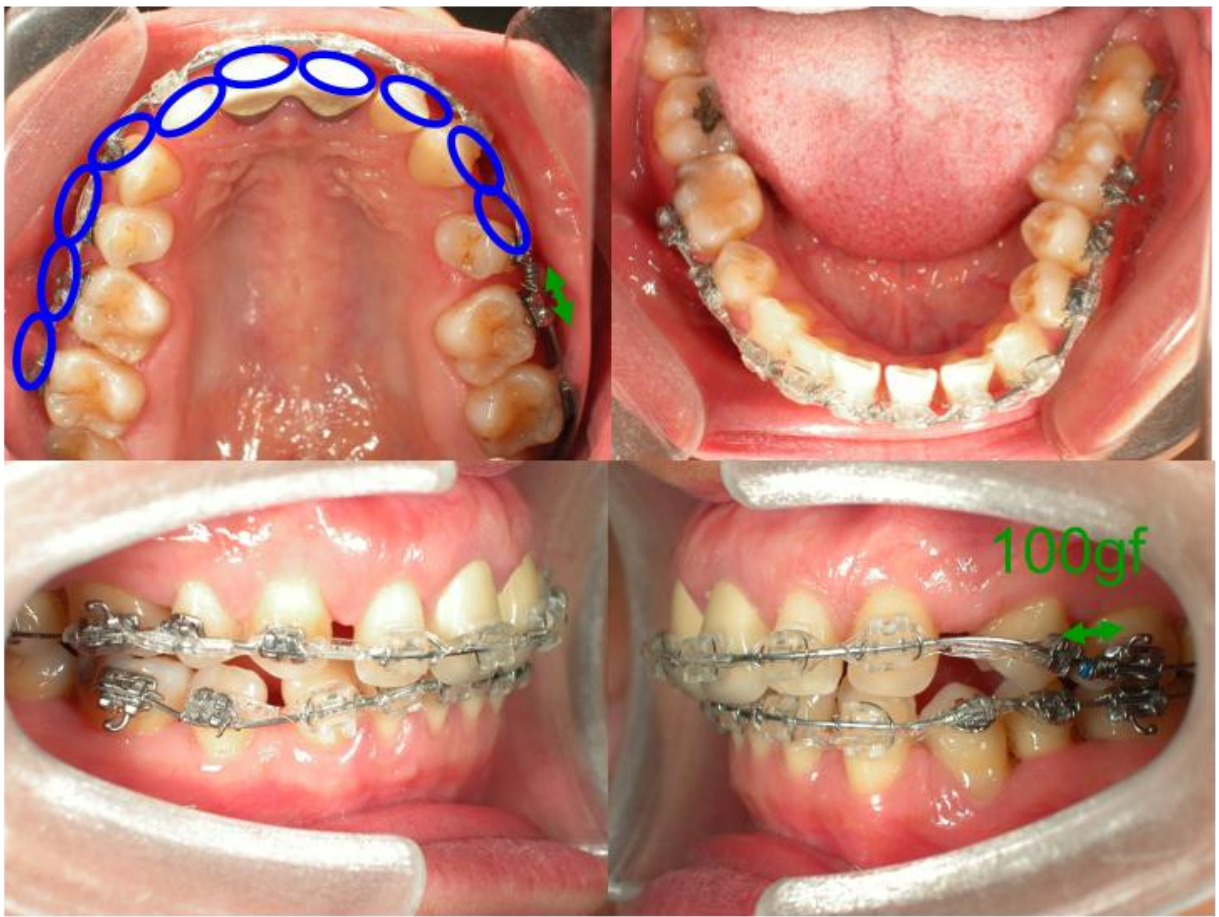

Figure 9: Period of active treatment: 5 month

After 9 months of active treatment, on 2005.12.05, unilateral ISW MEAW was used for crowding relief. Unilateral ISW MEAW was added over \#36 to \#37 to provide space and posterior anchorage for \#35 de-rotation. In the meantime, \#45 not-in-slot was used for better cusp interdigitation. (Fig.10) 
International Journal of Innovative Research in Medical Science (IJIRMS)

Volume 04 Issue 01 Jan 2019, ISSN: 2455-8737, Imp. Factor - 4.102

Available online at $-\underline{w w w . i j i r m s . i n}$

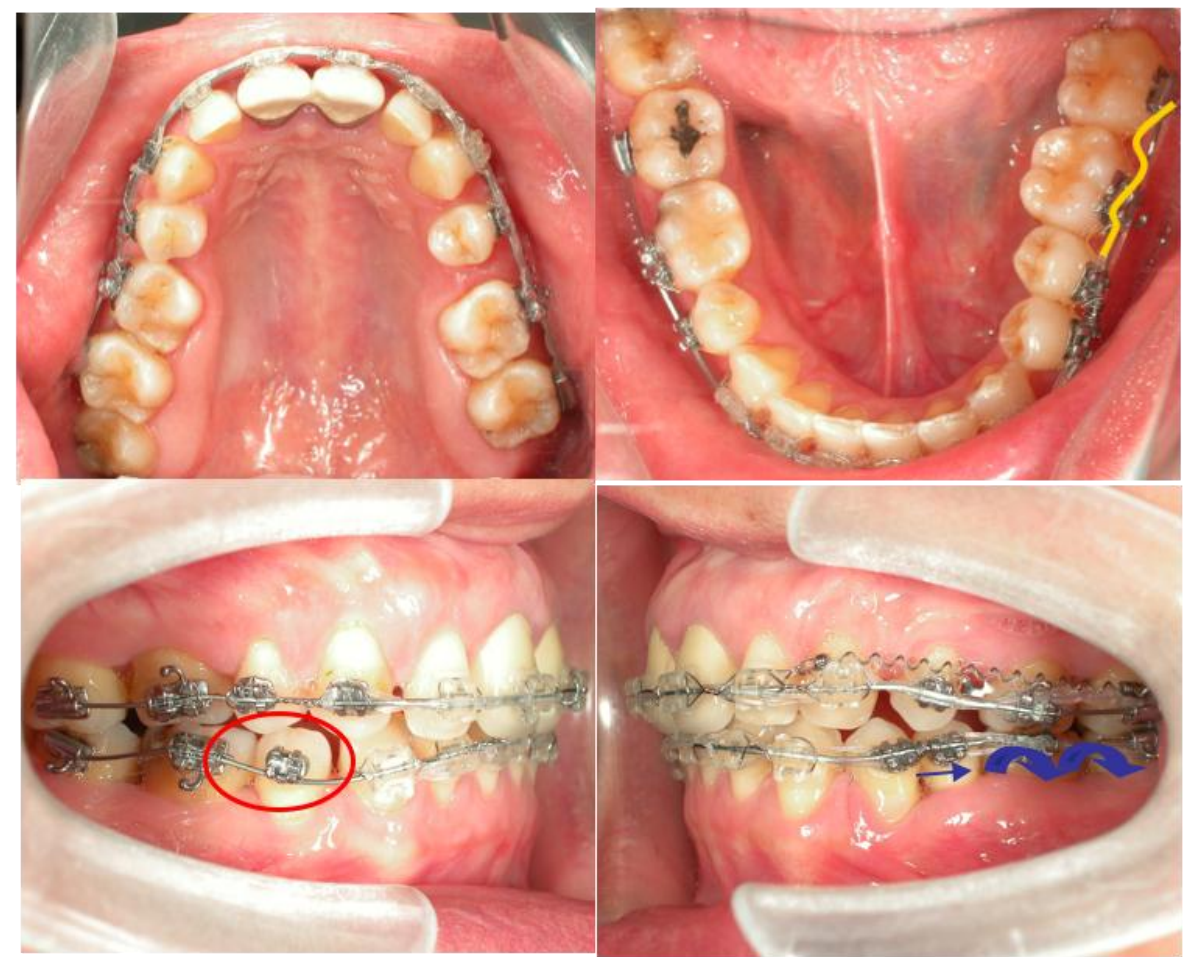

Figure 10: Period of active treatment: 9 months

\section{Treatment Results}

After 12 months of active treatment, on 2006.03.08, root parallelism was checked and re-bonding of teeth for ideal root parallelism. Space on the upper and lower arches was closed with elastic chain, and IME (inter-maxillary elastics) were used to achieve better cusp inter-digitation and the facilitation of \#26 mesialization. (Fig.11)

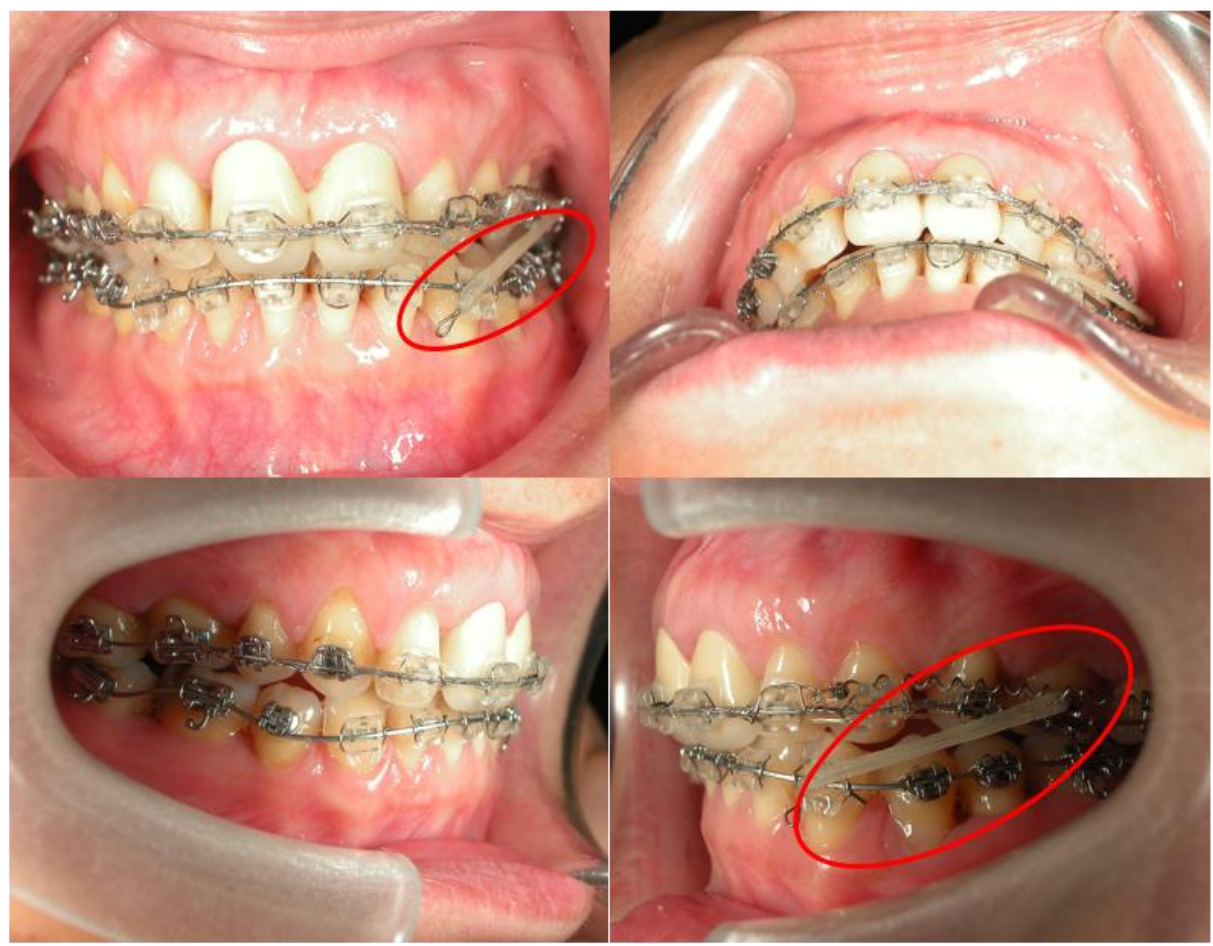

Figure 11: Period of active treatment: 12 months

For the total treatment time of 18 months, a stable occlusion was achieved and esthetic appearance was improved after the treatment. (Fig. 12\&13) 
International Journal of Innovative Research in Medical Science (IJIRMS)

Volume 04 Issue 01 Jan 2019, ISSN: 2455-8737, Imp. Factor - 4.102

Available online at - www.ijirms.in
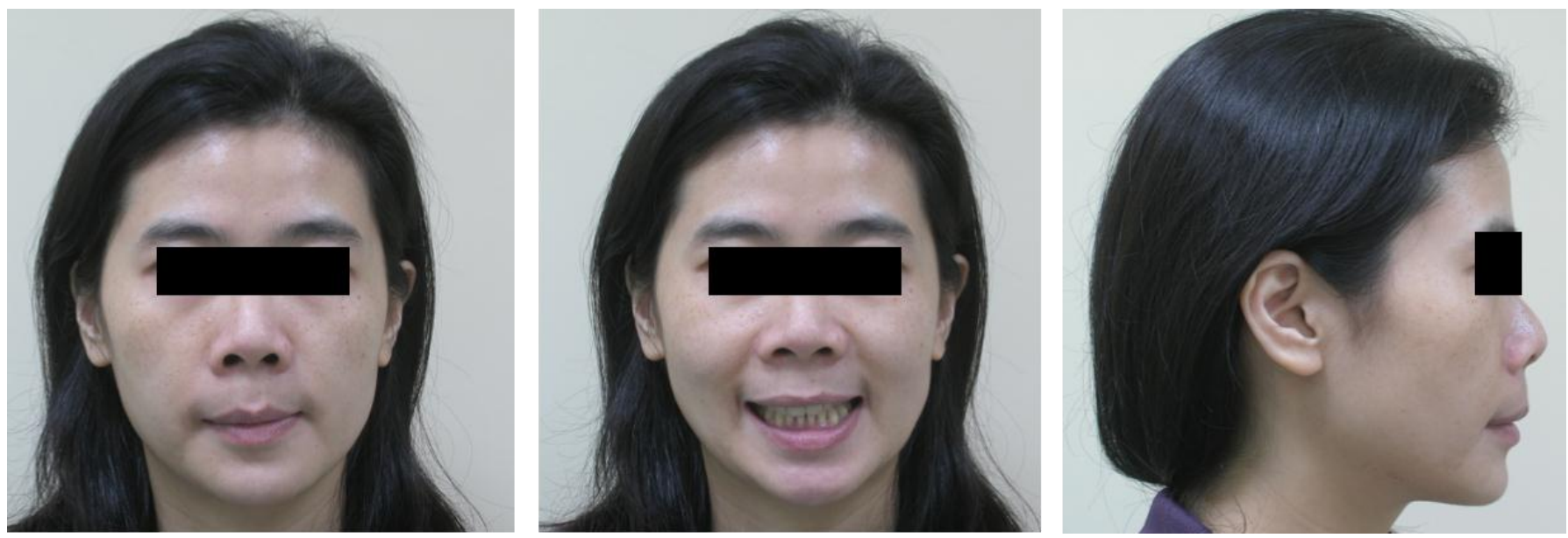

Figure 12: Facial photos after active treatment

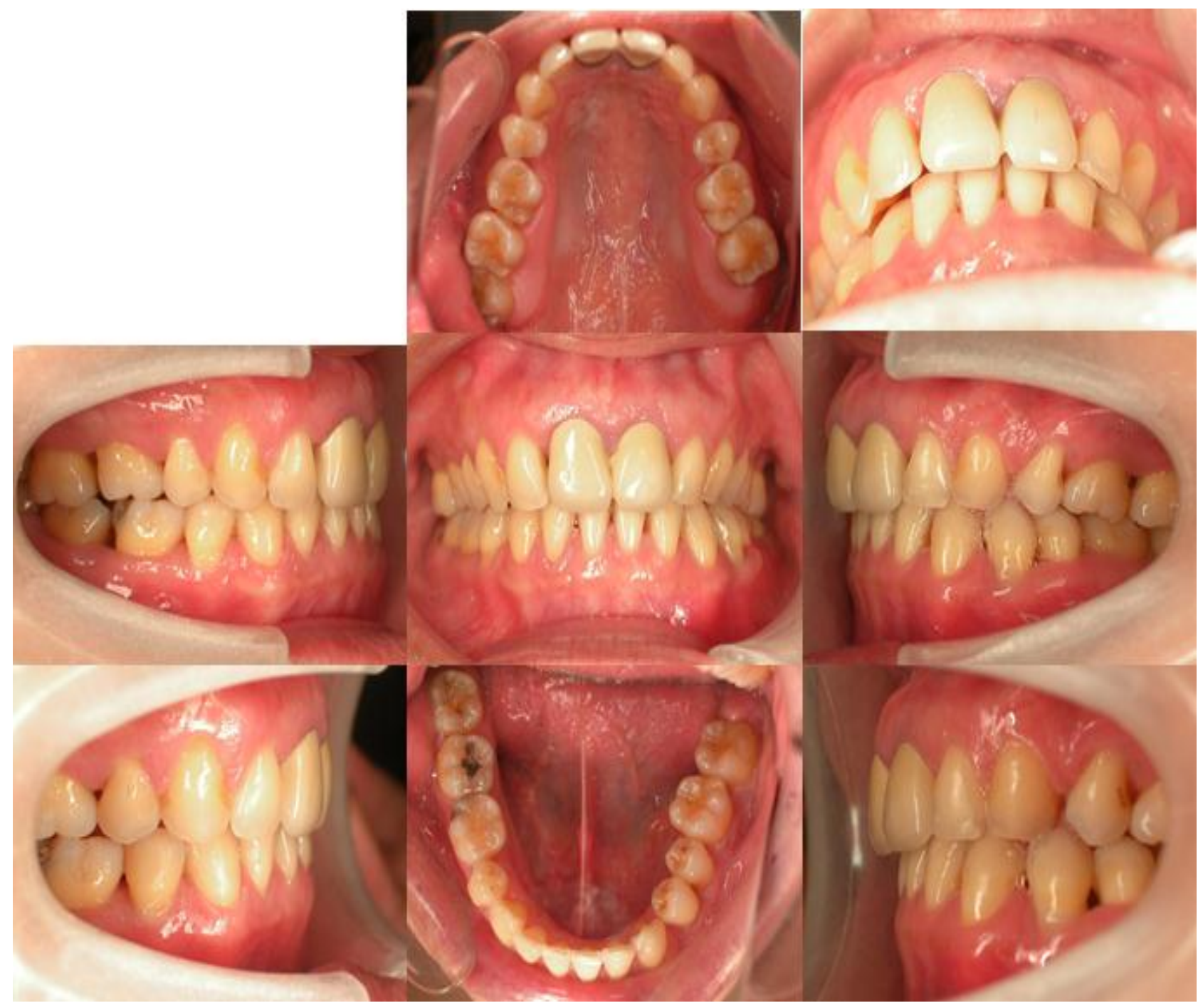

Figure 13: Intraoral photos after active treatment 
International Journal of Innovative Research in Medical Science (IJIRMS)

Volume 04 Issue 01 Jan 2019, ISSN: 2455-8737, Imp. Factor - 4.102

Available online at $-\underline{w w w . i j i r m s . i n}$

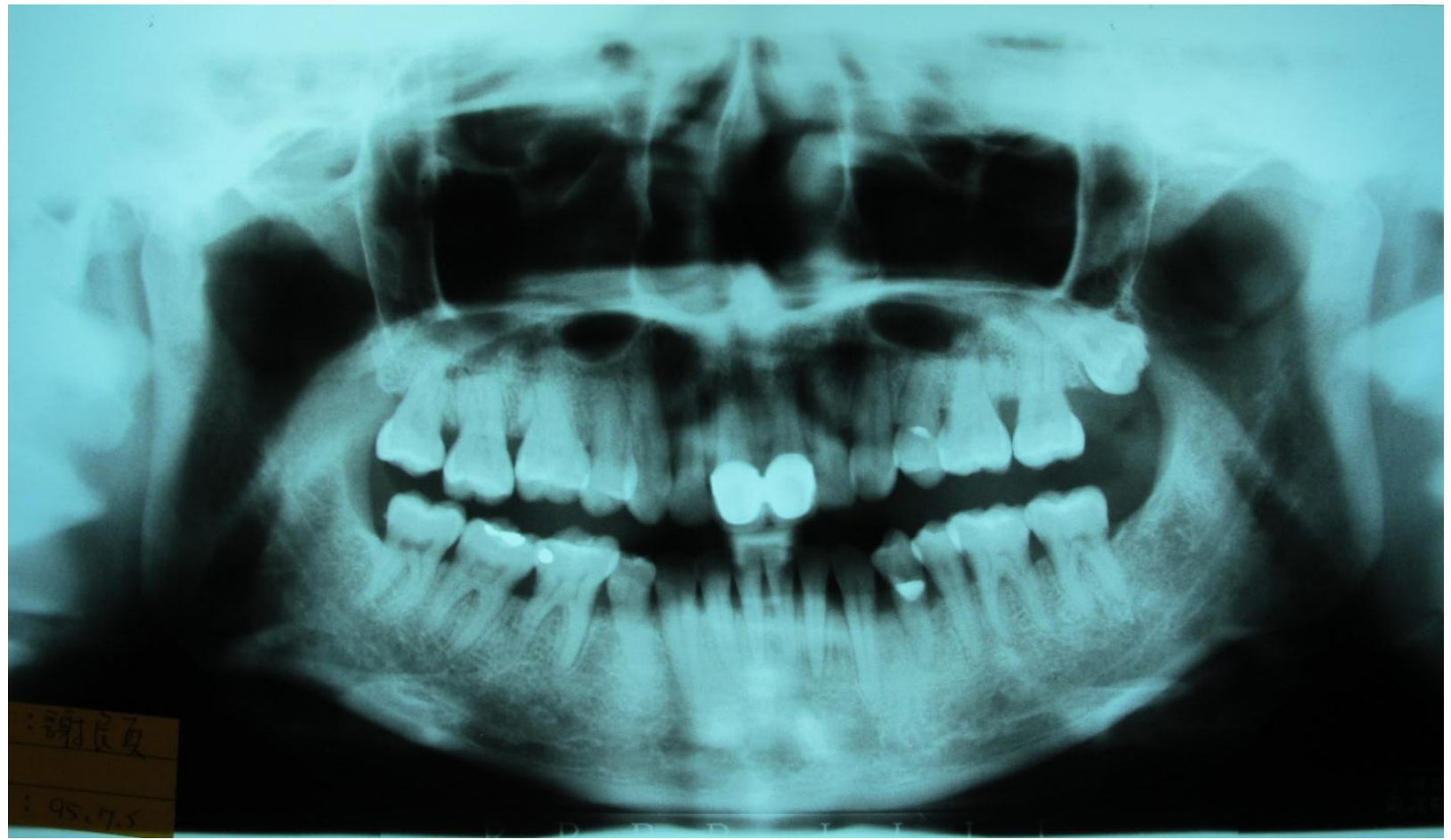

Figure 14: Panoramic film after active treatment
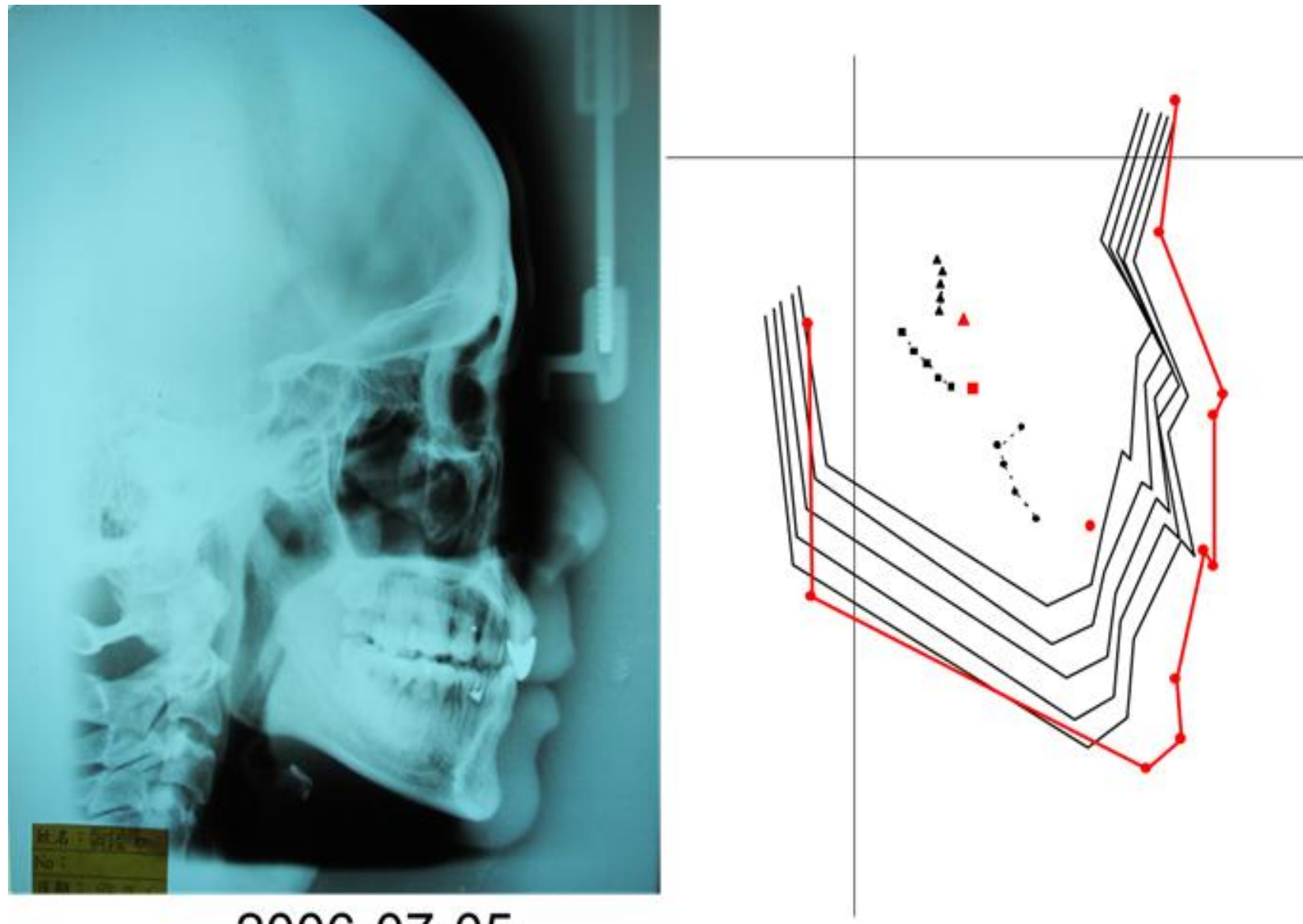

2006-07-05

Figure 15: Lateral Cephalometric film after active treatment 


\section{Polygon - after active treatment}

\begin{tabular}{|c|c|c|c|}
\hline & Before & After & Mean. \\
\hline Facial angle & 91.9 & 90.5 & 84.83 \\
\hline Convexity & 13.2 & 13.6 & 7.58 \\
\hline A-B plane & -10.7 & -9.2 & -4.81 \\
\hline Mandibular plane & 20.6 & 20.9 & 28.81 \\
\hline $\mathrm{Y}$-axis & 58.4 & 60.6 & 65.38 \\
\hline Occlusal plane & 12.8 & 14.6 & 11.42 \\
\hline Interincisal & 138.0 & 162.4 & 124.09 \\
\hline L-1 to Occlusal & 12.6 & -1.1 & 23.84 \\
\hline L-1 to Mandibular & 94.8 & 82.6 & 96.33 \\
\hline U-1 to A-P plane & 7.4 & 3.3 & 8.92 \\
\hline FMIA & 64.5 & 76.5 & 54.63 \\
\hline $\mathrm{FH}$ to $\mathrm{SN}$ plane & 9.2 & 9.2 & 6.19 \\
\hline SNA & 89.3 & 88.2 & 82.32 \\
\hline SNB & 81.9 & 80.8 & 78.90 \\
\hline SNA-SNB diff. & 7.4 & 7.4 & 3.39 \\
\hline U-1 to N-P plane & 11.0 & 7.3 & 11.74 \\
\hline U-1 to FH plane & 106.5 & 94.1 & 111.13 \\
\hline $\mathrm{U}-1$ to $\mathrm{SN}$ plane & 97.3 & 84.9 & 104.54 \\
\hline Gonial angle & 110.6 & 107.0 & 122.23 \\
\hline Ramus inclination & 90.0 & 93.9 & 87.07 \\
\hline
\end{tabular}

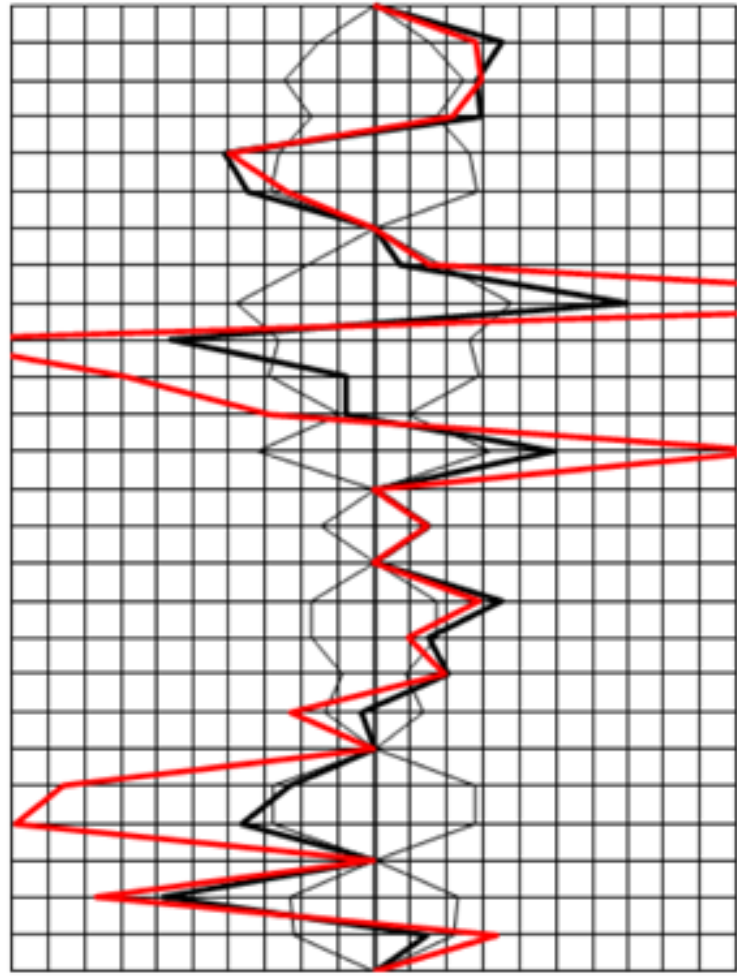

Figure 16: Polygon after active treatment

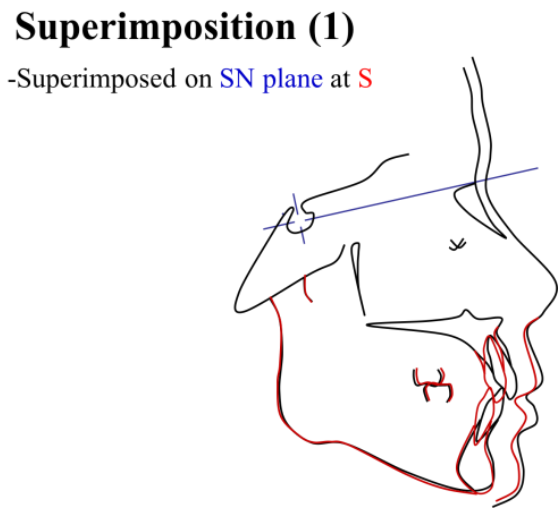

\section{Superimposition (2)}

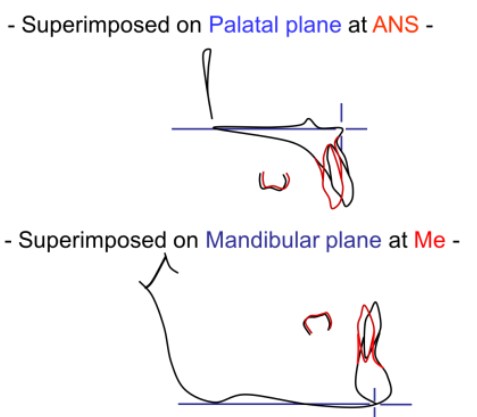

Figure 17: Superimposition after active treatment

After 18 months period of orthodontic active treatment, lateral cephalometric projection and panoramic x-ray films was taken, polygon and superimposition after active treatment was analyzed and denture pattern improved prominently (U1 to FH plane : $106.5^{\circ} \rightarrow 94.1^{\circ}$ 、 Inter-incisal angle : $\left.138.0^{\circ} \rightarrow 162.4^{\circ}\right)$. And the change of skeletal pattern was also considerable noticed after active treatment $\left(\mathrm{SNA}: 89.3^{\circ} \rightarrow 88.2^{\circ}, \mathrm{SNB}:\right.$ $81.9^{\circ} \rightarrow 80.8^{\circ}$, ANB $: 7.4^{\circ} \rightarrow 7.4^{\circ}$ ) (Fig. 14 17)

\section{Discussion}

Conventional orthodontic treatment of severely rotated tooth requires multiple arch-wire changing process. By ISW leveling, one can perform correction of rotated teeth and torque control at the same time. Therefore, deviated and rotated teeth can be treated with ISW leveling under a favorable torque control. ${ }^{[13-18]}$

\section{Not-in-slot}

It is not necessary to change the bracket position or to do wire bending when we want to intrude or extrude a tooth to a small extent. In this case, arch-wire was not engaged into the bracket slot, it was under the bracket (not-in-slot). We can use the not-inslot technique for single tooth (45) extrusion to the occlusal plane without re-bonding the bracket. (Fig.18) 
International Journal of Innovative Research in Medical Science (IJIRMS)

Volume 04 Issue 01 Jan 2019, ISSN: 2455-8737, Imp. Factor - 4.102

Available online at $-\underline{w w w . i j i r m s . i n}$

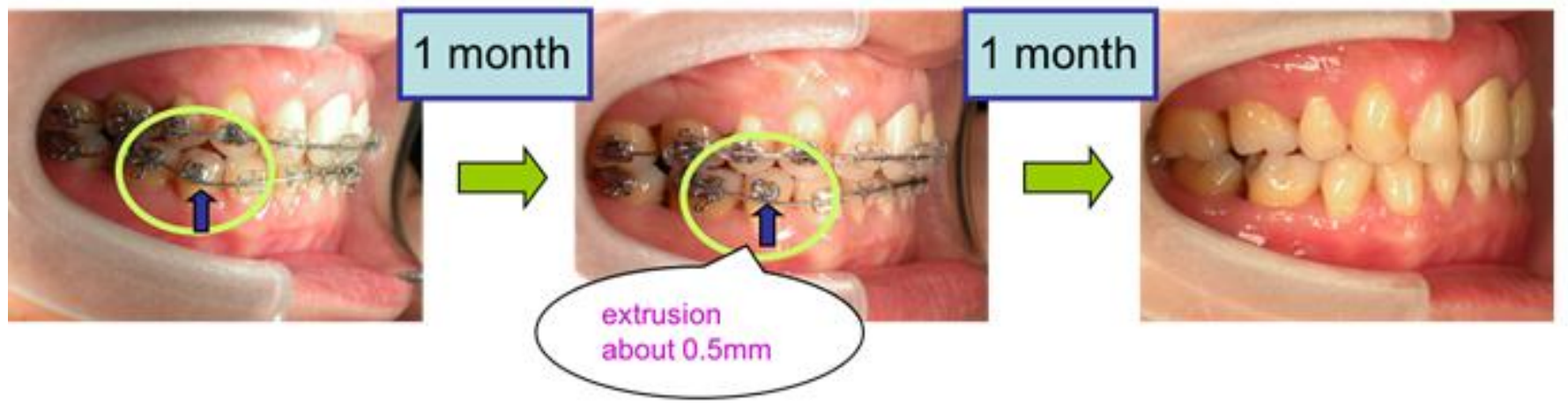

Figure 18 : Not-in-slot

\section{Correction of tooth axis}

We used elastic chain and bracket full engagement to correct tooth axis over \#31, \#32, \#41, \#42 effectively. (Figure.19)

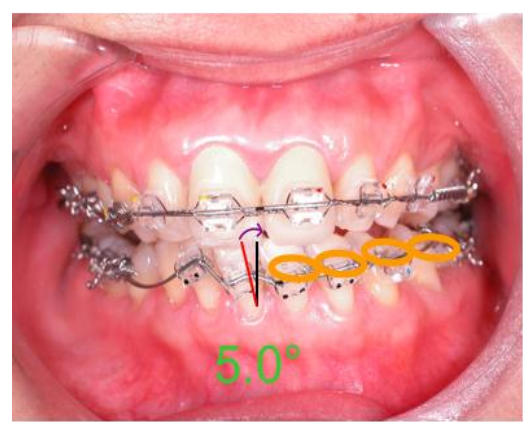

2005-03-25

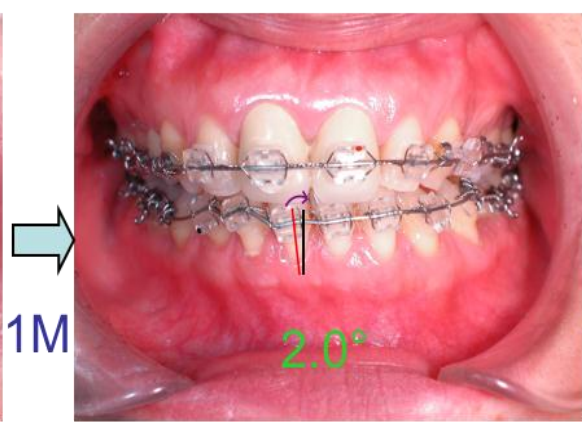

2005-04-22

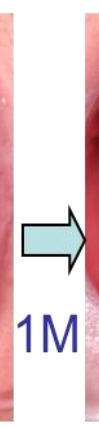

M

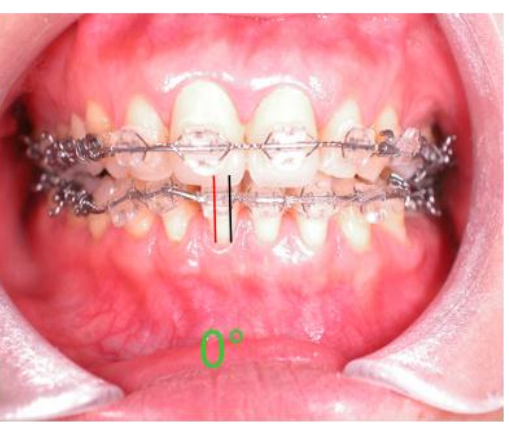

2005-05-13
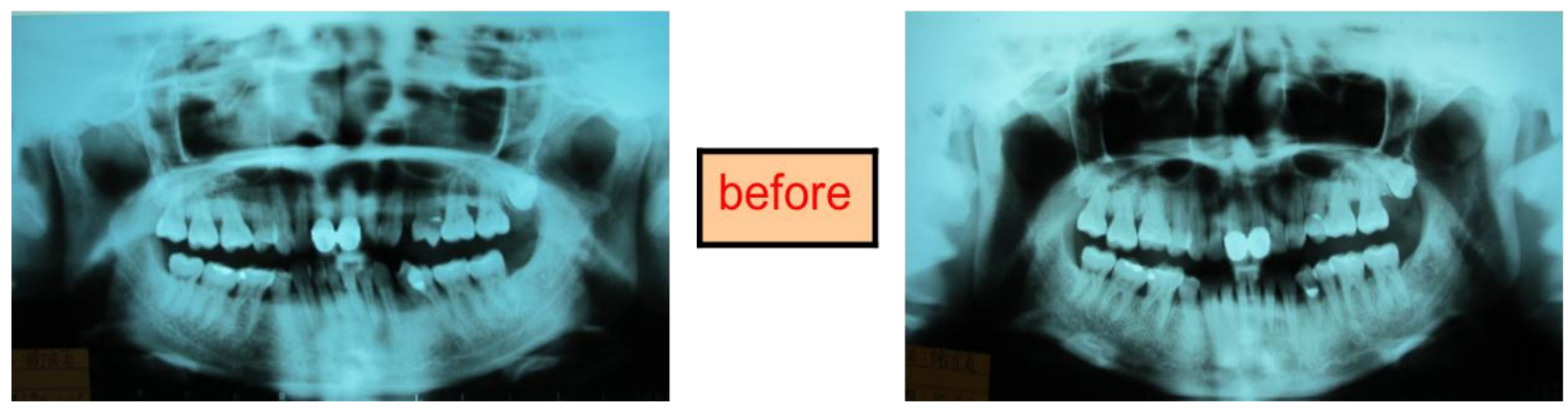

Figure 19: Correction of tooth axis

How to prevent anterior incisors from retroclining during posterior tooth mesialization?

Preventing anterior incisors from retroclining during posterior tooth mesialization requires two aspects of discussion listed below:

1. How can anterior anchorage be reinforced?

- A hook on the ISW to make the intra-arch and inter-arch anchorage easily acquired
- $\quad$ Adding compensating curve

- Serial ligature tying of anterior teeth

2. How can the posterior teeth be mesially moved more effectively?

- Wire size reduction

- Individual tooth protraction

- Mini-screw can be an alternative, but is sometimes criticized for its invasiveness. (Figure.20) 
International Journal of Innovative Research in Medical Science (IJIRMS)

Volume 04 Issue 01 Jan 2019, ISSN: 2455-8737, Imp. Factor - 4.102

Available online at $-\underline{w w w . i j i r m s . i n}$
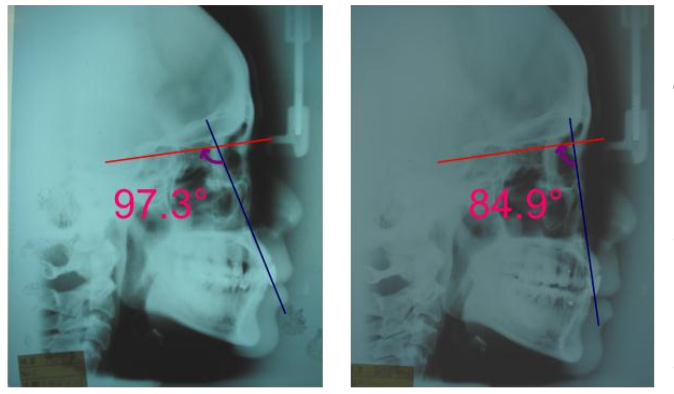

before after

We found a change in the $\mathrm{U} 1$ axis from the cephalometric film.

\section{How can anterior anchorage be reinforced?}

- A hook on the ISW to make the intra-arch and inter-arch anchorage easily acquired

- Add compensating curve

- Serial ligature tying of anterior teeth
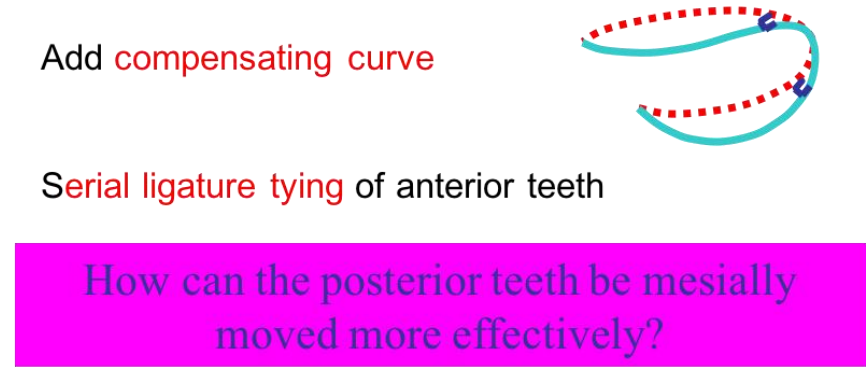

- Wire size reduction

- Individual tooth protraction

- Mini-screw can be an alternative, but is sometimes criticized for its invasiveness.

Figure 20: How to prevent anterior incisors from retroclining during posterior tooth mesialization?

\section{De-rotation}

At the initial time of active treatment, \#25 showed a rotation of about 85 degrees. After one month, bracket was placed mesial to \#25 and elastic chain was used to correct rotation. After 3 months of active treatment, \#25 re-DBS was performed and was fully engaged. And after 5 months of active treatment, open coil-spring was placed between \#25 and \#26 to facilitate \#25 de-rotation. Finally, at 9 months of time after active treatment, rotation was corrected. (Figure.21)
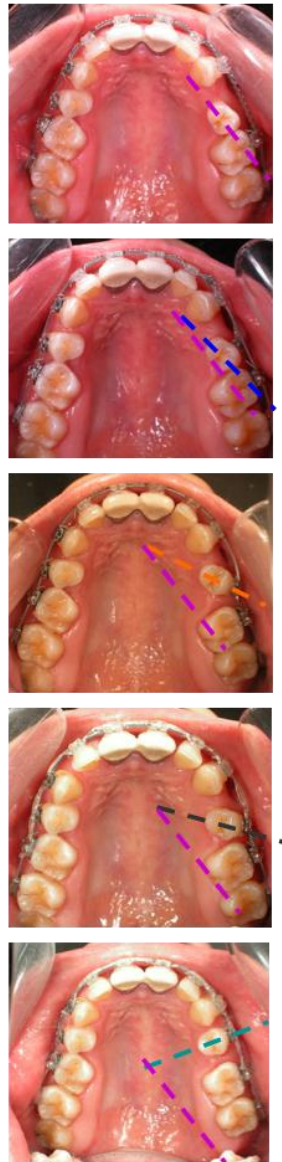

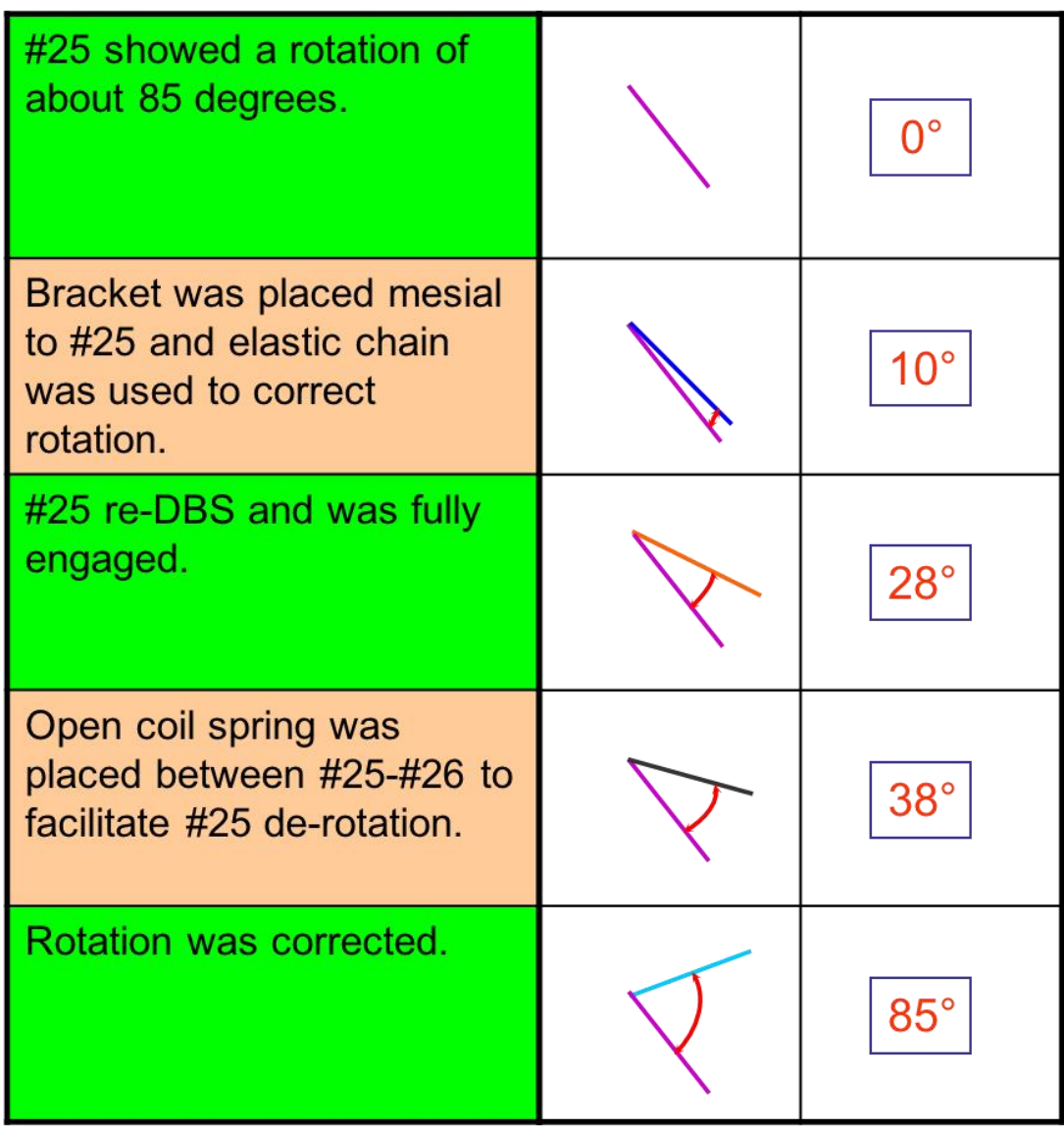

Figure 21 : De-rotation 


\section{Conclusion}

Treatment of deviated and rotated teeth by ISW (Improved Superelastic Ti-Ni alloy wire, developed by Tokyo Medical and Dental University) was discussed in the article. With successful ISW treatment, lower deviated teeth were corrected efficiently. Rotation of lower left and right premolars were corrected simply by ISW leveling. For correction of rotated upper left second premolar, NiTi open coil-spring was placed to create space for bracket bonding on the \#25 buccal surface. ISW was fully engaged into \#25 and then rotation was corrected by further leveling. After 18 months of active treatment, a stable occlusion and a desirable esthetic outcome was achieved and the patient was pleased with the treatment result after the active treatment.

Conventional orthodontic treatment of severely rotated tooth requires multiple arch-wire changing process. But by using ISW, relative tipping and favorable torqueing control can be performed at the same time. To conclude, deviated and rotated teeth can lead to compromised dental and facial aesthetics and therefore requires appropriate treatment, adult patient case with deviated and rotated teeth can be treated with ISW treatment.

\section{Reference}

[1] Angle, E. H.: Treatment of malocclusion of the teeth, ed. 7, Philadelphia, 1907, S. S. White Dental Manufacturing Company.

[2] Brain, W. E. (1969). "The effect of surgical transsection of free gingival fibers on the regression of orthodontically rotated teeth in the dog."American Journal of Orthodontics 55(1): 50-70.

[3] Edwards, J. G. (1968). "A study of the periodontium during orthodontic rotation of teeth."American Journal of Orthodontics 54(6): 441-461.

[4] Edwards, J. G. (1970). "A surgical procedure to eliminate rotational relapse."American Journal of Orthodontics and Dentofacial Orthopedics 57(1): 35-46.
[5] Reitan, K. (1959). "Tissue rearrangement during retention of orthodontically rotated teeth."The Angle Orthodontist 29(2): 105-113.

[6] SWANSON, W. D., et al. (1975). "Postretention study: incidence and stability of rotated teeth in humans."The Angle Orthodontist 45(3): 198-203.

[7] Boese, L. R.: Increased stability of orthodontically rotated teeth, Aor. J. ORTHODONTICS 66: 273-290, 1969.

[8] Brain, W. E.: The effect of surgical trans-section of free gingival fibers on the regression of orthodontically rotated teeth in the dog, AM. J. ORTHODONTICS 44: 485497, 1958.

[9] Brauer, J. S.: A surgical procedure to reduce the tension in trans-septal fibers of orthodontically rotated teeth, M.Sc.0. Thesis, University of North Carolina, 1963.

[10] Case, C. S.: Principles of retention in orthodontia, INT. J. ORTHOEQNTIA 6: 627-638, 1920

[11] Eccles, J. D.: Studies on the development of the periodontal membrane: The principal fibers of the molar teeth, D. Practitioner \& D. Record 10: 31-35, 1959.

[12] Edwards, J. G.: A study of the periodontium during orthodontic rotation of teeth, Ax J. ORTHODONTICS 54: 441.459, 1968.

[13] Reitan, K.: Experiments of rotation of teeth and their subsequent retention, Tr. European Orthodont. Sot. 34: 124-140, 1958.

[14] Reitan, K.: Retention a11d avoidance of posttreatment relapse, AM. J. ORTHODONTICS 66:784, 1969.

[15] Reitan, K.: Tissue rearrangement during retention of orthodontically rotated teeth, Angle Orthodontist 29: 105-113, 1959.

[16] Sicher, II.: Vistas in orthodontics, Pl1iladelphia, 1962, Lea \& Febiger, pp. 81-83.

[17] Sicher, II.: Orban's oral histology and embryology, ed. 5, St. Louis, 1962, The C. V. Mosby Company, pp. 185192.

[18] Sicher, H.: Tooth eruption: The axial movement of continuously growing teeth, J. D. Res. 21: 201-210, 1942. 